\title{
B-type (brain) natriuretic peptide and pruritus in hemodialysis patients
}

This article was published in the following Dove Press journal: International Journal of Nephrology and Renovascular Disease 25 August 2014

Number of times this article has been viewed

\author{
Yoshio Shimizu \\ Ayano Sonoda \\ Chieko Nogi \\ Yoko Ogushi \\ Reo Kanda \\ Saori Yamaguchi \\ Nao Nohara \\ Tatsuya Aoki \\ Kaori Yamada \\ Junichiro Nakata \\ Hiroaki lo \\ Atsushi Kurusu \\ Chieko Hamada \\ Satoshi Horikoshi \\ Yasuhiko Tomino \\ Division of Nephrology, Department \\ of Internal Medicine, Juntendo \\ University Faculty of Medicine, \\ Tokyo, Japan
}

Introduction and objective: While pruritus is a common complication in hemodialysis patients, the pathophysiological mechanisms remain obscure. Recently, B-type (brain) natriuretic peptide (BNP) has been defined as an itch-selective neuropeptide in pruriceptive neurons in mice, and higher serum levels of BNP are frequently observed in hemodialysis patients. The objective of the present study was to evaluate the role of serum BNP in pruritus in patients undergoing hemodialysis.

Patients and methods: The current cross-sectional study was performed on 43 patients undergoing maintenance hemodialysis. A visual analog scale (VAS) measuring the general severity of pruritus (values from 0 to 10 , with higher values indicating more severe pruritus) in daytime and at night was self-reported by patients. Each patient's background and laboratory tests, including serum BNP in the post-hemodialysis period, were collected. The correlation between VAS and clinical parameters was evaluated.

Results: Both daytime and nighttime VAS scores in diabetic patients were significantly less than those in nondiabetic patients. Multiple regression analysis revealed that pruritus in daytime was worsened by serum BNP $(\beta=2.0, t=2.4, P=0.03)$, calcium $(\beta=4.4, t=5.2, P<0.0001)$, and $\beta_{2}$-microglobulin $(\beta=2.0, t=3.0, P=0.007)$, while it was eased by age $(\beta=-2.2, t=-3.2, P=0.0004)$. Nocturnal pruritus was severe in nondiabetic patients $(\beta=1.7, t=3.8, P=0.0005)$ and weakened by the total iron binding capacity $(\beta=-2.9, t=-3.1, P=0.004)$

Conclusion: It is suggested that a higher level of serum BNP increases the pruritus of hemodialysis patients in daytime and that diabetic patients are less sensitive to itch, especially at nighttime.

Keywords: B-type brain natriuretic peptide, pruritus, hemodialysis, visual analog scale, itchselective neuropeptide, pruriceptive neurons, cerebrospinal fluid

\section{Introduction}

Pruritus is a common and serious problem among hemodialysis patients. ${ }^{1}$ A brief literature review showed that pruritus is a problem with a large variation of incident rates between countries as well as between facilities ( $36 \%-50 \%$ and $5 \%-75 \%$, respectively). In Japan, severity of patient-reported pruritus symptoms experienced over a 4-week period was collected from 6,480 patients undergoing hemodialysis in three phases of the Dialysis Outcomes and Practice Patterns Study ([DOPPS] 1996-2008; 60-65 study facilities/phase). ${ }^{2}$ Moderate-to-extreme pruritus was experienced by $44 \%$ of Japanese patients undergoing maintenance hemodialysis. ${ }^{2}$ Many patient characteristics were significantly associated with pruritus but did not explain the large differences in incidence rates in pruritus among facilities $(20 \%-70 \%){ }^{2}$ Patients with moderate-to-severe pruritus were more likely to feel drained and have poor sleep quality and lower quality of life
Division of Nephrology, Department of Internal Medicine, Juntendo University Faculty of Medicine, 2-I-I Hongo, Bunkyo-ku, Tokyo, I|3-842।, Japan

Tel +81358021065

$\mathrm{Fax}+81338131183$

Email yasu@juntendo.ac.jp (c) (i) (5) 2014 Shimizu et al. This work is published by Dove Medical Press Limited, and licensed under Creative Commons Attribution - Non Commercial (unported, v3.0) BY LC License. The full terms of the License are available at http://creativecommons.org/licenses/by-nc/3.0/. Non-commercial uses of the work are permitted without any further permission from Dove Medical Press Limited, provided the work is properly attributed. Permissions beyond the scope of the License are administered by Dove Medical Press Limited. Information on how to request permission may be found at: http://www.dovepress.com/permissions.php 
(mental and physical composite score) than patients with no/ mild pruritus. ${ }^{2}$ Pruritus in patients undergoing hemodialysis was associated with a $17-23 \%$ higher mortality risk. ${ }^{1,2}$ It has been suggested that the relationship between pruritus and higher mortality risk associated with hemodialysis patients might be explained in large part by pruritus leading to sleep disturbances. ${ }^{1}$

Despite an apparent reduction in recent years, perhaps because of advances in hemodialysis, this symptom still occurs with unacceptably high frequency among end-stage kidney disease patients. ${ }^{1,2}$

Effective treatment options are limited, and the mechanism of uremic pruritus is multifactorial and not fully understood. ${ }^{3}$ A randomized crossover trial of a $\mu$-opioid agonist, naltrexone, failed to relieve the uremic patients with pruritus. ${ }^{4,5} \mathrm{~A} \kappa$-opioid receptor agonist, nalfurafine, has been demonstrated to cause a moderate reduction in pruritus among hemodialysis patients. ${ }^{6}$ Although other approaches and combination therapies have been tried, a sufficient reduction in pruritus has not been achieved. ${ }^{7}$ Continuous epidural administration of Butorphanol (Stadol, Bristol-Myers Squibb, New York, NY, USA), a commercially available $\kappa$-opioid agonist and $\mu$-opioid antagonist, relieved pruritus associated with epidural morphine infusion in children, and the patients with intractable pruritus associated with inflammatory skin diseases or systemic diseases showed rapid and marked improvement by intranasal administration with Butorphanol. ${ }^{8,9}$ These findings suggest that Butorphanol is a potential therapeutic agent against uremic pruritus.

Itching is triggered by somatosensory neurons expressing the ion channel TRPV1 (transient receptor potential cation channel subfamily V member 1). ${ }^{10}$ Recently, Mishra and Hoon reported that the natriuretic polypeptide $b(\mathrm{Nppb})$ is expressed within a subset of TRPV1 neurons and is characterized as an itch-selective neuropeptide in mice. ${ }^{11} \mathrm{Nppb}$ is also known as B-type (brain) natriuretic peptide (BNP). ${ }^{12}$ Although elevated levels of serum BNP are commonly observed in hemodialysis patients, the relationship between pruritus and BNP has not been revealed. The objective of the present study was to evaluate the role of serum BNP in pruritus in patients undergoing hemodialysis.

\section{Patients and methods}

The current cross-sectional study was performed on 43 patients (31 males and 13 females) undergoing maintenance hemodialysis at the Juntendo University Hospital, Tokyo, Japan. Patients who had undergone incidental hemo- dialysis and maintenance hemodialysis within the 3 months preceding the study were excluded. Baseline characteristics were examined from the computed records of the Juntendo University Hospital; these included: age; sex; the cause of renal failure; post-dialysis BNP; dialysis vintage (year); hemoglobin levels; hematocrit; serum iron; total iron binding capacity (TIBC); ferritin; calcium; phosphorus; albumin; intact parathyroid hormone; pre-dialysis and post-dialysis blood urea nitrogen; pre-dialysis and post-dialysis creatinine; aspartate aminotransferase (AST); alanine aminotransferase (ALT); $\gamma$-glutamyl transpeptidase $(\gamma$-GTP); total bilirubin; hepatitis B surface antigen and anti-hepatitis $\mathrm{C}$ virus with the third generation; triglyceride, low-density lipoprotein cholesterol; and C-reactive protein. There were two groups of patients, comprising those undergoing hemodialysis on Mondays, Wednesdays, and Fridays (group 1) and those undergoing hemodialysis on Tuesdays, Thursdays, and Saturdays (group 2). The blood samples were collected from the patients in group 1 on June 17, 2013 (Monday) and from those in group 2 on June 18, 2013 (Tuesday). The blood was obtained just before initiation of hemodialysis as predialysis sample and just before termination of the session as post-dialysis sample. The patients with diabetes mellitus (DM) who showed microalbuminuria (Kidney Disease Improving Global Outcomes [KDIGO] CKD albuminuria A2) progressed to proteinuria (KDIGO CKD albuminuria A3), progressive renal impairment in their clinical course were regarded the cause of end-stage kidney disease as diabetic nephropathy. The diagnosis was confirmed by the presence of diabetic retinopathy. A questionnaire was used to assess patients' pruritus. The questionnaires were completed during the hemodialysis session when blood samples were collected. The patients were asked to report on the severity of both their daytime and nighttime pruritus on a visual analog scale (VAS) graded from 0 to 10 , with grade 0 representing no discomfort and grade 10 representing unbearably severe pruritus. The distribution of scratching episodes and what stimulated their itch sense were also asked as well as VAS score.

The study protocol was approved by the Ethics Review Committee of Juntendo University Faculty of Medicine, Tokyo, Japan and complied with the tenets of the Declaration of Helsinki of 1975. All participants provided written informed consent.

\section{Statistical analysis}

All data are expressed as the mean \pm standard deviation. Comparisons of continuous variables were analyzed 
using an unpaired $t$-test. Simple regression analysis was performed between daytime or nighttime VAS and other clinical parameters. To determine a suitable combination of variables, an Akaike's Information Criterion (AIC) ${ }^{13}$ of each different model was applied on a round robin of explanatory variables including age, serum BNP, TIBC, ferritin, calcium, pre-dialysis creatinine, $\beta 2$-microglobulin, and C-reactive protein. The combination variable that showed minimum AIC was selected for the multiple regression analysis. ${ }^{13}$ All statistical examinations were performed using JMP 10 software (SAS Institute Inc., Cary, NC, USA), and $P<0.05$ was considered to be statistically significant.

Table I Clinical characteristics of the patients enrolled in the study

\begin{tabular}{|c|c|c|c|}
\hline & Unit & $\begin{array}{l}\text { Normal } \\
\text { range }\end{array}$ & $\begin{array}{l}\text { Mean } \\
\text { value } \pm \text { SD }\end{array}$ \\
\hline Age & Years & & $63.5 \pm 10.3$ \\
\hline Sex & Male/female & & $31 / 13$ \\
\hline Cause of renal failure & DM/non-DM & & $|3 / 3|$ \\
\hline Daily VAS & & & $2.3 \pm 2.7$ \\
\hline Nocturnal VAS & & & $3.1 \pm 3.3$ \\
\hline Post-dialysis BNP & & & $217.2 \pm 257.8$ \\
\hline Dialysis vintage & Years & & $8.1 \pm 6.1$ \\
\hline Hemoglobin & $g / d L$ & $13-18$ & $\mid \mathrm{I} . \mathrm{I} \pm 0.8$ \\
\hline Hematocrit & $\%$ & $40-52$ & $34.1 \pm 2.5$ \\
\hline Iron & $\mathrm{mg} / \mathrm{dL}$ & $60-200$ & $64.6 \pm 34$ \\
\hline TIBC & $\mathrm{mg} / \mathrm{dL}$ & $250-410$ & $277 \pm 47.6$ \\
\hline Ferritin & $\mathrm{ng} / \mathrm{mL}$ & $20-280$ & $64 \pm 70.1$ \\
\hline Calcium & $\mathrm{mg} / \mathrm{dL}$ & $8.2-10$ & $9.1 \pm 0.5$ \\
\hline Albumin & $\mathrm{mg} / \mathrm{dL}$ & $3.7-5.5$ & $3.8 \pm 0.3$ \\
\hline Phosphorus & $\mathrm{mg} / \mathrm{dL}$ & $2.5-4.5$ & $5.5 \pm 1.2$ \\
\hline Intact PTH & $\mathrm{Pg} / \mathrm{mL}$ & $10-65$ & $147 \pm 107.9$ \\
\hline Pre-dialysis BUN & $\mathrm{mg} / \mathrm{dL}$ & $<20$ & $63.9 \pm 13$ \\
\hline Post-dialysis BUN & $\mathrm{mg} / \mathrm{dL}$ & $<20$ & $20.2 \pm 5.2$ \\
\hline Pre-dialysis creatinine & $\mathrm{mg} / \mathrm{dL}$ & $0.6-1.0$ & $11.3 \pm 2.3$ \\
\hline Post-dialysis creatinine & $\mathrm{mg} / \mathrm{dL}$ & $0.6-1.0$ & $4.6 \pm 2.8$ \\
\hline$\beta_{2}$-microglobulin & $\mathrm{mg} / \mathrm{L}$ & $5-250$ & $24.7 \pm 6.1$ \\
\hline AST & $\mathrm{IU} / \mathrm{L}$ & $<40$ & II. $2 \pm 4.6$ \\
\hline $\mathrm{ALT}$ & $\mathrm{IU} / \mathrm{L}$ & $<40$ & $8.9 \pm 2.6$ \\
\hline$\gamma$-GTP & IU/L & $<50$ & $23.3 \pm 23.6$ \\
\hline Hepatitis B surface antigen & Positive/negative & & $0 / 44$ \\
\hline $\begin{array}{l}\text { Anti-hepatitis C antibody } \\
\text { (3rd) }\end{array}$ & Positive/negative & & $1 / 43$ \\
\hline Total bilirubin & $\mathrm{mg} / \mathrm{dL}$ & $<1.0$ & $0.4 \pm 0.1$ \\
\hline Triglyceride & $\mathrm{mg} / \mathrm{dL}$ & $50-150$ & $120.8 \pm 53.2$ \\
\hline LDL-cholesterol & $\mathrm{mg} / \mathrm{dL}$ & $<140$ & $90.5 \pm 21.2$ \\
\hline C-reactive protein & $\mathrm{mg} / \mathrm{dL}$ & $<0.1$ & $0.3 \pm 0.5$ \\
\hline
\end{tabular}

Notes: The normal range of each parameter is set for the general population. Abbreviations: $\gamma$-GTP, $\gamma$-glutamyl transpeptidase; ALT, alanine aminotransferase; AST, aspartate aminotransferase; BNP, B-type (brain) natriuretic peptide; BUN, blood urea nitrogen; DM, diabetes mellitus; LDL, low-density lipoprotein; PTH, parathyroid hormone; SD, standard deviation; TIBC, total iron binding capacity; VAS, visual analog scale.

\section{Results}

\section{Characteristics of the patients enrolled in this study}

Baseline patient characteristics are summarized in Table 1. The daytime and nighttime VAS scores were $2.3 \pm 2.7$ and 3.1 \pm 3.3 , respectively, which showed a positive correlation $\left(r^{2}=0.23, P=0.001\right)$. The patients' $\mathrm{DM} /$ non-DM ratio was 13/31 (Table 1), and other clinical parameters were controlled within the recommended range based on the guidelines for maintenance hemodialysis from the Japanese Society for Dialysis Therapy. ${ }^{14}$

Distributions of scratching episodes varied among the patients, but $52 \%$ of the patients suffered from pruritus on the back and $25 \%$ on the lower limbs (Table 2). Pruritus was induced by dry conditions in $43 \%$ of the patients; from contact with a blanket or synthetic fibers in $30 \%$; and by sweating in $30 \%$ (Table 3 ).

\section{Impact of diabetes status on pruritus severity}

The mean daytime VAS in DM patients was $1.0 \pm 1.3$, while that in non-DM patients was $2.9 \pm 3.0(P<0.05)$. The nighttime VAS in DM patients was significantly less than that in non-DM patients $(0.9 \pm 1.6$ versus $4.1 \pm 3.4, P<0.01)$ (Figure 1). The cause of renal failure (DM or non-DM) was adopted as a candidate multiple regression analysis.

\section{Simple regression analysis between VAS and clinical parameters}

Of the studied clinical parameters, serum BNP $\left(r^{2}=0.05\right.$, $P=0.13)$, calcium $\left(r^{2}=0.04, P=0.17\right)$, pre-dialysis creatinine $\left(r^{2}=0.08, P=0.06\right), \beta_{2}$-microglobulin $\left(r^{2}=0.11, P=0.1\right)$, and C-reactive protein $\left(r^{2}=0.053, P=0.13\right)$ showed a weak or

Table 2 Distributions of scratching episodes in hemodialysis patients

\begin{tabular}{lll}
\hline & \multicolumn{2}{l}{ Scratching episodes (n=44) } \\
\cline { 2 - 3 } & Yes, $\mathbf{n}(\%)$ & No, $\mathbf{n}(\%)$ \\
\hline Head & I (2) & $43(98)$ \\
Face & $2(5)$ & $42(95)$ \\
Neck & $5(1 \mathrm{I})$ & $39(89)$ \\
Upper limbs & $8(18)$ & $36(82)$ \\
Breast & $2(5)$ & $42(95)$ \\
Abdomen & $5(1 \mathrm{I})$ & $39(89)$ \\
Inguinal region & $2(5)$ & $42(95)$ \\
Hip & $2(5)$ & $42(95)$ \\
Back & $23(52)$ & $21(48)$ \\
Lower limbs & II (25) & $33(75)$ \\
\hline
\end{tabular}


Table 3 Pruritus stimulatory situation in hemodialysis patients

\begin{tabular}{lll}
\hline & \multicolumn{2}{l}{ Itchy feeling $(\mathbf{n}=\mathbf{4 4})$} \\
\cline { 2 - 3 } & Yes, $\mathbf{n}(\%)$ & No, $\mathbf{n}(\%)$ \\
\hline Dry conditions & $19(43)$ & $25(57)$ \\
Contact with blanket or synthetic fibers & $13(30)$ & $31(70)$ \\
Sweating & $13(30)$ & $31(70)$ \\
Bathing & $8(18)$ & $36(82)$ \\
Relaxed situation & $7(16)$ & $37(84)$ \\
Stressful situation & $6(14)$ & $38(86)$ \\
\hline
\end{tabular}

mild correlation with daytime VAS (Table 4). BNP $\left(r^{2}=0.07\right.$, $P=0.09)$, TIBC $\left(r^{2}=0.12, P=0.02\right)$, serum calcium $\left(r^{2}=0.059\right.$, $P=0.11)$, post-dialysis creatinine $\left(r^{2}=0.05, P=0.17\right)$, $\beta_{2}$-microglobulin $\left(r^{2}=0.11, P=0.11\right)$, and $\mathrm{C}$-reactive protein $\left(r^{2}=0.053, P=0.13\right)$ were weakly correlated to nighttime VAS (Table 4).

\section{Impact of serum BNP on pruritus severity}

Multiple regression analysis revealed that age $(\beta=-2.2$, $t=-3.2, P=0.0004)$, BNP $(\beta=2.0, t=2.4, P=0.03)$, TIBC $(\beta=2.3, t=2.9, P=0.009)$, serum calcium $(\beta=4.4, t=5.2$, $P<0.0001)$, and $\beta_{2}$-microglobulin $(\beta=2.0, t=3.0, P=0.007)$ were statistically significant independent factors for daytime VAS (Figure 2A). On the other hand, BNP was not shown as an independent factor of nighttime VAS. Only DM as the cause of renal failure ( $\beta=-1.7, t=-3.8, P=0.0005)$ and TIBC ( $\beta=-2.9, t=-3.1, P=0.004)$ were revealed as significant independent factors for nighttime VAS.

\section{Discussion}

BNP was initially isolated from a porcine brain extract, which is homologous to, but definitively distinct from, atrial natriuretic peptide (ANP) in terms of its amino acid sequence. ${ }^{15}$ Since it was later clarified that cardiomyocytes mainly produce BNP, BNP was renamed "B-type natriuretic peptide", from its previous "brain natriuretic peptide". ${ }^{16}$

It has been reported that BNP is a neuropeptide in pruriceptive neurons. ${ }^{11}$ Mice intrathecally given BNP showed a scratch response. ${ }^{11}$ This finding suggests that a high concentration of BNP in cerebrospinal fluid activates pruriceptive neurons, resulting in itching.

BNP has been considered as an objective practical guide to better tailoring drug treatment to patients with chronic heart failure. ${ }^{17}$ Higher concentrations of serum BNP are frequently observed in poorly weight-controlled hemodialysis patients. We initially thought the concentration of serum BNP was directly linked to that of cerebrospinal fluid (CSF) but CSF is not generally regarded as an ultrafiltrate or dialysate of plasma. ${ }^{18}$ Moreover, the correlation of BNP in serum and CSF in hemodialysis patients is unknown. The simultaneous measurement of BNP in serum and cerebrospinal fluid has been rarely reported. N-terminal pro-B-type natriuretic peptide (NT-proBNP) in cerebrospinal fluid and serum is more significantly elevated in patients with severe traumatic brain injury, whose intracranial pressure is over $15 \mathrm{mmHg}$, than in those in whom this is under $15 \mathrm{mmHg} .{ }^{19}$ This report suggests that the level of intrathecal BNP is responsible for increased intracranial pressure.

The increased venous pressure is transmitted to dural venous sinuses and veins within the cranial cavity. The increased pressure in the intracranial veins, dural sinuses, and jugular veins results in decreased absorption of cerebrospinal fluid. An increased amount of fluid may accumulate in the cisterns around the brain, arachnoid spaces, and, sometimes, within cerebral ventricles, resulting in increased

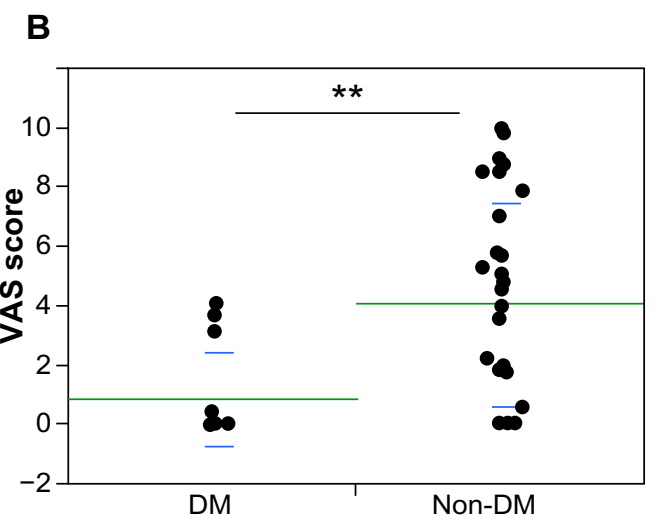

Figure I Impact of serum BNP on pruritus severity.

Notes: Hemodialysis patients with DM and without DM (non-DM) were compared with VAS at daytime (A) and nighttime (B). Both daytime and nighttime VAS scores in DM patients were significantly lower than in non-DM patients $(* P<0.05$, $* * P<0.01$, respectively).

Abbreviations: BNP, B-type (brain) natriuretic peptide; DM, diabetes mellitus; VAS, visual analog scale. 
Table 4 Simple regression analysis for pruritus in daytime and nighttime related clinical parameters in hemodialysis patients

\begin{tabular}{|c|c|c|c|c|c|c|}
\hline & \multicolumn{3}{|c|}{ Versus VAS (daytime) } & \multicolumn{3}{|c|}{ Versus VAS (nighttime) } \\
\hline & $r^{2}$ & F-value & $P$-value & $r^{2}$ & $F$-value & $P$-value \\
\hline Age & 0.006 & 0.27 & 0.6 & 0.002 & 0.08 & 0.79 \\
\hline BNP & 0.05 & 2.4 & 0.13 & 0.07 & 3 & 0.09 \\
\hline Dialysis vintage & 0.002 & 0.07 & 0.8 & 0.03 & 1.09 & 0.3 \\
\hline Hemoglobin & 0.002 & 0.07 & 0.96 & 0.01 & 0.44 & 0.5 \\
\hline Hematocrit & 0.001 & 0.06 & 0.81 & 0.03 & 1.24 & 0.27 \\
\hline Iron & 0.004 & 0.18 & 0.68 & 0.0001 & 0.006 & 0.94 \\
\hline TIBC & 0.0003 & 0.01 & 0.9 & 0.12 & 5.67 & 0.02 \\
\hline Ferritin & 0.04 & $\mathrm{I} .4$ & 0.24 & 0.0005 & 0.02 & 0.88 \\
\hline Calcium & 0.04 & 1.8 & 0.17 & 0.059 & 2.64 & 0.11 \\
\hline Albumin & 0.004 & 0.18 & 0.67 & 0.01 & 0.44 & 0.51 \\
\hline Phosphorus & 0.002 & 0.08 & 0.78 & 0.01 & 0.47 & 0.5 \\
\hline Intact PTH & 0.03 & 1.2 & 0.29 & 0.002 & 0.1 & 0.76 \\
\hline Pre-dialysis BUN & 0.0001 & 0.005 & 0.94 & 0.001 & 0.04 & 0.83 \\
\hline Post-dialysis BUN & 0.0007 & 0.03 & 0.87 & 0.012 & 0.51 & 0.48 \\
\hline Pre-dialysis creatinine & 0.08 & 3.7 & 0.06 & 0.038 & 1.67 & 0.2 \\
\hline Post-dialysis creatinine & 0.03 & 1.2 & 0.27 & 0.05 & 2 & 0.17 \\
\hline$\beta_{2}$-microglobulin & 0.11 & 2.9 & 0.1 & 0.11 & 2.7 & 0.11 \\
\hline AST & 0.008 & 0.3 & 0.56 & 0.008 & 0.34 & 0.56 \\
\hline ALT & 0.03 & 1.13 & 0.29 & 0.026 & 1.13 & 0.29 \\
\hline$\gamma$-GTP & 0.02 & 0.72 & 0.39 & 0.02 & 0.73 & 0.4 \\
\hline Total bilirubin & 0.007 & 0.14 & 0.7 & 0.007 & 0.14 & 0.7 \\
\hline Triglyceride & $<0.0001$ & 0 & 0.99 & $<0.0001$ & 0 & 0.99 \\
\hline LDL-cholesterol & 0.002 & 0.06 & 0.8 & 0.002 & 0.06 & 0.81 \\
\hline C-reactive protein & 0.053 & 2.35 & 0.13 & 0.053 & 2.35 & 0.13 \\
\hline Sex & & & 0.4 & & & 0.7 \\
\hline
\end{tabular}

Abbreviations: $\gamma$-GTP, $\gamma$-glutamyl transpeptidase; AST, aspartate aminotransferase; ALT, alanine aminotransferase; BNP, B-type (brain) natriuretic peptide; BUN, blood urea nitrogen; LDL, low-density lipoprotein; PTH, parathyroid hormone; TIBC, total iron binding capacity; VAS, visual analog scale.

\begin{tabular}{|c|c|c|c|c|c|}
\hline A & $\beta$ & 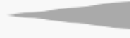 & Itch & $t$ value & $P$-value \\
\hline Intercept & 1.7 & $: \vdots: \vdots$ & ; & 5.7 & 0.0004 \\
\hline Age & -2.2 & 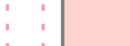 & $:$ & -3.2 & 0.005 \\
\hline BNP & 2.0 & : : : & $:$ & 2.4 & 0.03 \\
\hline TIBC & 2.3 & $: \vdots: \vdots$ & $\because$ & 2.9 & 0.009 \\
\hline $\mathrm{Ca}$ & 4.4 & $\begin{array}{l}\vdots \\
\vdots\end{array}$ & & 5.2 & $<0.0001$ \\
\hline$\beta_{2}-M G$ & 2.0 & $\begin{array}{l}1 \\
\vdots\end{array}$ & : & 3.0 & 0.007 \\
\hline
\end{tabular}

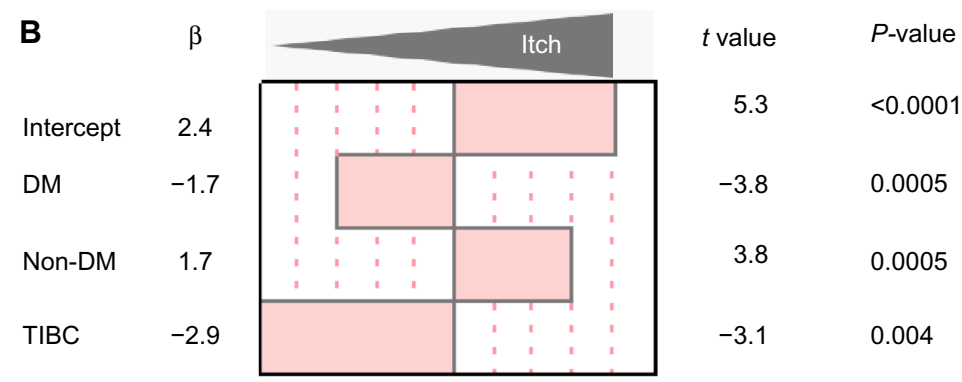

Figure 2 Multiple regression analysis for clinical parameters related to pruritus in hemodialysis patients.

Notes: (A) The standardized regression coefficients in clinical parameters for daytime VAS in hemodialysis patients. Serum BNP is significantly related to worsening daytime pruritus in hemodialysis patients. (B) The standardized regression coefficients for nighttime VAS.

Abbreviations: $\beta_{2}-$ MG, $\beta_{2}$-microglobulin; BNP, B-type (brain) natriuretic peptide; DM, diabetes mellitus; TIBC, total iron binding capacity; VAS, visual analog scale. 
intracranial pressure. ${ }^{20}$ Increased systemic venous pressure is common in hemodialysis patients and in chronic renal failure patients with increased intracranial pressure dramatically improved by hemodialysis. ${ }^{21}$ Other patients with chronic renal failure suffering from intracranial hypertension have been clearly relieved by renal transplantation. ${ }^{22}$ Most hemodialysis patients have an arteriovenous fistula/graft or central venous cannulization, which compress the venous system. Severe venous congestive encephalopathy resulting from arteriovenous graft and cerebral hemorrhage due to internal jugular vein stenosis has been reported as cerebral venous hypertension. ${ }^{23,24}$ Thus, hemodialysis patients are at high risk for venous hypertension resulting in intracranial hypertension. These conditions induce a high level BNP in both serum and CSF.

Other candidates in this study that are associated with pruritus in hemodialysis patients have been previously reported. ${ }^{3,25}$ TIBC is also a potential cause of pruritus-related clinical parameters. ${ }^{26}$ In this study, TIBC was considered an enhancer of daytime itching and an attenuator of nighttime itching (Figure 2). Nocturnal pruritus diminishes the quality of life by increasing sleep disturbances. It has been noted that nocturnal pruritus is different from that which occurs in the daytime and is possibly related to the circadian rhythm of itch mediators and skin temperature. ${ }^{27}$ The Janus-faced function of TIBC is possibly associated with the differences between daytime and nighttime pruritus.

In this study, diabetic patients showed significantly lower VAS in daytime and nighttime than nondiabetic patients. Most diabetic hemodialysis patients have diabetic peripheral neuropathy. ${ }^{28}$ Pruritus is mediated by unmyelinated C-fibers and thinly myelinated $A \delta$-fiber afferents. ${ }^{29}$ Neuropathic pruritus is common in patients with diabetic peripheral neuropathy and arises from damage to unmyelinated C-fibers. ${ }^{30}$ $\mathrm{C}$-fibers have been divided into peptidergic and non-peptidergic subsets, mainly on the basis of neurochemical criteria. A large subset of peptidergic neurons expresses TRPV1, and TRPV1 knockout mice show deficits in histamine-evoked scratch response. ${ }^{10}$ A recent report suggested that TRPV1 expression is altered in the streptozotocin-induced and transgene-mediated type- 1 diabetes mouse model. ${ }^{31}$ Thus, it is suggested that pruritus signals were blocked not only by damaged $\mathrm{C}$-fibers, but also by reduced expression of receptors.

\section{Limitation}

This was a small cross-sectional study based on a single center.

\section{Conclusion}

Serum BNP is one possible cause of daytime pruritus in hemodialysis patients. Since it is possible to lower the level of serum BNP by lowering target dry weight and minimizing weight gain in hemodialysis intervals of patients undergoing hemodialysis, lowering the BNP level favors patients suffering from pruritus.

\section{Acknowledgment}

The authors thank all the staff of the hemodialysis unit in Juntendo University Hospital.

\section{Author contributions}

YS, AK, CH, SH and YT designed the study. AS, CN, YO, RK, SY, NN, TA, KY, JN and HI helped to collect VAS and clinical data. YS analyzed data and drafted the manuscript. All authors took part in revising the manuscript. The final version was read and approved by all authors.

\section{Disclosure}

The authors report no conflicts of interest in this work.

\section{References}

1. Pisoni RL, Wikström B, Elder SJ, et al. Pruritus in haemodialysis patients: international results from the Dialysis Outcomes and Practice Patterns Study (DOPPS). Nephrol Dial Transplant. 2006;21: 3495-3505.

2. Kimata N, Fuller DS, Saito A, et al. Pruritus in hemodialysis patients: results from the Japanese Dialysis Outcomes and Practice Patterns Study (JDOPPS). Hemodial Int. 2014;18:657-667.

3. Narita I, Iguchi S, Omori K, Gejyo F. Uremic pruritus in chronic hemodialysis patients. J Nephrol. 2008;21:161-165.

4. Peer G, Kivity S, Agami O, et al. Randomised crossover trial of naltrexone in uraemic pruritus. Lancet. 1996;348:1552-1554.

5. Pauli-Magnus C, Mikus G, Alscher DM, et al. Naltrexone does not relieve uremic pruritus: results of a randomized, doubleblind, placebo-controlled crossover study. J Am Soc Nephrol. 2000;11:514-519.

6. Kumagai H, Ebata T, Takamori K, Muramatsu T, Nakamoto H, Suzuki H. Effect of a novel kappa-receptor agonist, nalfurafine hydrochloride, on severe itch in 337 haemodialysis patients: a Phase III, randomized, double-blind, placebo-controlled study. Nephrol Dial Transplant. 2010;25:1251-1257.

7. Mettang T, Kremer AE. Uremic pruritus. Kidney Int. Epub January 8, 2014.

8. Gunter JB, McAuliffe J, Gregg T, Weidner N, Varughese AM, Sweeney DM. Continuous epidural butorphanol relieves pruritus associated with epidural morphine infusions in children. Paediatr Anaesth. 2000;10:167-172.

9. Dawn AG, Yosipovitch G. Butorphanol for treatment of intractable pruritus. J Am Acad Dermatol. 2006;54:527-531.

10. Imamachi N, Park GH, Lee H, et al. TRPV1-expressing primary afferents generate behavioral responses to pruritogens via multiple mechanisms. Proc Natl Acad Sci U S A. 2009;106:11330-11335.

11. Mishra SK, Hoon MA. The cells and circuitry for itch responses in mice. Science. 2013;340:968-971. 
12. Natriuretic peptide precursor B; NPPB [webpage on the Internet]. OMIM 600295. Baltimore, MD: Johns Hopkins University; 1995 [updated September 12, 2013]. Available from: http://omim.org/ entry/600295. Accessed August 7, 2014.

13. Akaike H. A new look at the statistical model identification. IEEE Transactions on Automatic Control. 1974;19(6):716-723.

14. Mizuguchi J, Tomo T, Masakane I, et al. JSDT 'Guidelines for Maintenance Hemodialysis: Hemodialysis Prescriptions'. J Jpn Soc Dial Ther. 2013;46:587-632. Japanese.

15. Sudoh T, Kangawa K, Minamino N, Matsuo H. A new natriuretic peptide in porcine brain. Nature. 1988;332:78-81.

16. Nakao K, Mukoyama M, Hosoda K, et al. Biosynthesis, secretion, and receptor selectivity of human brain natriuretic peptide. Can J Physiol Pharmacol. 1991;69:1500-1506.

17. De Vecchis R, Esposito C, Di Biase G, Ariano C, Giasi A, Cioppa C. B-type natriuretic peptide-guided versus symptom-guided therapy in outpatients with chronic heart failure: a systematic review with metaanalysis. J Cardiovasc Med (Hagerstown). 2014;15:122-134.

18. Mortazavi MM, Griessenauer CJ, Adeeb N, et al. The choroid plexus: a comprehensive review of its history, anatomy, function, histology, embryology, and surgical considerations. Childs Nerv Syst. 2014;30:205-214.

19. Kirchhoff C, Stegmaier J, Bogner V, et al. Intrathecal and systemic concentration of NT-proBNP in patients with severe traumatic brain injury. J Neurotrauma. 2006;23:943-949.

20. Caplan LR. Cardiac encephalopathy and congestive heart failure: a hypothesis about the relationship. Neurology. 2006;66:99-101.

21. Chang D, Nagamoto G, Smith WE. Benign intracranial hypertension and chronic renal failure. Cleve Clin J Med. 1992;59:419-422.
22. Mourani CC, Mallat SG, Moukarzel MY, Akatcherian CY, Cochat P. Kidney transplantation after a severe form of pseudotumor cerebri. Pediatr Nephrol. 1998;12:709-711.

23. Samaniego EA, Abrams KJ, Dabus G, Starr R, Linfante I. Severe venous congestive encephalopathy secondary to a dialysis arteriovenous graft. J Neurointerv Surg. 2013;5:e37.

24. Saha MK, Hamieh T, Larkin B, Mcmillan W. Cerebral hemorrhage due to internal jugular vein stenosis in a hemodialysis patient. Clin Exp Nephrol. 2012;16:345-349.

25. Lugon JR. Uremic pruritus: a review. Hemodial Int. 2005;9:180-188.

26. Stolić R, Trajković G, Perić V, Jovanović A, Lazarević T, SubarićGorgieva G. Parametres of clinical and biohumoral status of pruritus in patients on chronic haemodialysis. Med Pregl. 2007;60 Suppl 2: $101-103$.

27. Patel T, Ishiuji Y, Yosipovitch G. Nocturnal itch: why do we itch at night? Acta Derm Venereol. 2007;87:295-298.

28. Santoro D, Satta E, Messina S, Costantino G, Savica V, Bellinghieri G. Pain in end-stage renal disease: a frequent and neglected clinical problem. Clin Nephrol. 2013;79 Suppl 1:S2-S11.

29. Namer B, Carr R, Johanek LM, Schmelz M, Handwerker HO, Ringkamp M. Separate peripheral pathways for pruritus in man. J Neurophysiol. 2008;100:2062-2069.

30. Binder A, Koroschetz J, Baron R. Disease mechanisms in neuropathic itch. Nat Clin Pract Neurol. 2008;4:329-337.

31. Pabbidi RM, Yu SQ, Peng S, Khardori R, Pauza ME, Premkumar LS. Influence of TRPV1 on diabetes-induced alterations in thermal pain sensitivity. Mol Pain. 2008;4:9.

\section{Publish your work in this journal}

The International Journal of Nephrology and Renovascular Disease is an international, peer-reviewed open-access journal focusing on the pathophysiology of the kidney and vascular supply. Epidemiology, screening, diagnosis, and treatment interventions are covered as well as basic science, biochemical and immunological studies. The journal welcomes

\section{Dovepress}

original research, clinical studies, reviews \& evaluations, expert opinion and commentary, case reports and extended reports. The manuscript management system is completely online and includes a very quick and fair peerreview system, which is all easy to use. Visit http://www.dovepress.com/ testimonials.php to read real quotes from published authors 